\title{
The Role of Biology in an Engineering Program
}

\author{
Danny D. Mann \\ Department of Biosystems Engineering, University of Manitoba, Winnipeg, MB R3T 5V6 \\ Corresponding Author E-mail Address: Danny_Mann@umanitoba.ca
}

\begin{abstract}
Biology may not be a typical subject in the traditional engineering disciplines (i.e., civil, electrical, or mechanical), however, it is a fundamental component of disciplines such as biosystems engineering. Biosystems engineering emphasizes the application of engineering principles to biologically-based systems (i.e., systems that include plants, animals, microorganisms, or humans). A biosystems engineering program is designed to give students knowledge of the fundamental principles of engineering and to introduce biological concepts to enable these engineers to successfully interact with relevant professionals when solving engineering problems involving biological systems. The Department of Biosystems Enginering at the University of Manitoba offers five specializations (agricultural, biomedical, bioprocessing, environmental, and sustainable building systems) that can be taken within the biosystems engineering program. The purpose of this paper is to discuss the biology content of the biosystems engineering program at the University of Manitoba and to highlight the importance of biology to each of the five specializations.
\end{abstract}

Keywords: engineering curriculum, Biosystems engineering

\section{HISTORY OF BIOSYSTEMS ENGINEERING}

In 1905, the discipline of Agricultural Engineering was officially established in the USA. The mandate of this discipline was to increase agricultural productivity while decreasing the drudgery associated with the production of food. The earliest members of the discipline had been educated as civil, electrical, or mechanical engineers. These engineers began to apply engineering principles to problems related to agriculture in the following areas: power and machinery, soil and water, electric power and processing, and structures and environment. Until the early 1970 s, the focus of agricultural engineers remained at the farm level.

Modern agriculture has very little resemblance to agriculture in the early 1900s. Agricultural engineers cannot take all of the credit, but they did play a major role in increasing the efficiency of food production per unit of land area and in reducing the percentage of the population needed to provide food to feed society. Notable achievements by agricultural engineers include development of the agricultural tractor and self-propelled combine, rural electrification, conservation tillage practices, center pivot irrigation systems, and refrigerated on-farm milk storage. Despite the "success" of this discipline, it is becoming increasingly difficult to find an agricultural engineer (at least in North America). Where have they gone? The truth is that they now can be found under a new name such as biosystems engineer (or something similar). Using a business analogy, agricultural engineering has undergone a merger (and then a name change). The so-called merger occurred when agricultural engineers began working on off-farm problems. Agricultural engineers had established credibility in dealing with engineering problems involving plants and animals (based on inclusion of courses such as biology and physiology in the curriculum); it was only a small step to include topics such as ecology, microbiology, anatomy, or other similar sciences to equip these engineers to work in jobs related to food processing, pharmaceutical production, environmental protection, or rehabilitation engineering. A single name was needed to describe an engineer educated to work in any area where engineering was expected to consider biological factors. Thus, the discipline of Biosystems Engineering was born. At the University of Manitoba, the name of the Department of Agricultural Engineering officially changed to the Department of Biosystems Engineering in 1995.

The first substantive deviation from the traditional agricultural engineering curriculum was the creation of an "environmental option" which was jointly offered with the Department of Civil Engineering. Appropriate science courses such as ecology and microbiology were added to the curriculum and new technical electives were developed to provide education in topics such as 
environmental impact assessment, air pollution control, pollution prevention practices, and remediation engineering. Another initiative was to develop a food engineering program, however, funding was never obtained to offer such a program. The next initiative resulted from a consultation with the Faculty of Medicine. With selection of specified electives, graduates from the Biosystems Engineering program would have the required courses to apply to the Faculty of Medicine. As a consequence of this consultation, the Department members began to consider how the program might further evolve in the area of biomedical engineering.

At present, the Department of Bioystems Engineering offers a general Biosystems Engineering degree with the opportunity for students to tailor their education by pursuing one of five specializations (described below).

\section{SPECIALIZATIONS WITHIN BIOSYSTEMS ENGINEERING PROGRAM}

\subsection{Agricultural Specialization}

Challenges remain in the production of food for a world of ever-increasing population. There is a role to be played by engineers to increase the efficiency by which food is produced. Examples include developments in the design of machinery for food production and the design of controlled environments for both plant and animal production. For many decades, agricultural engineering programs have included introductory biology and physiology courses that have enabled engineering problems related to agriculture to be addressed successfully. Unfortunately, our planet still faces major challenges associated with producing and storing adequate supplies of food. Thus, the original reasons for incorporating biology into the curriculum of agricultural engineering programs still exist. The engineering student completing an agricultural specialization needs to have a basic understanding of plants and animals in order to implement effective solutions.

The agricultural specialization consists of electives in three categories. Students are required to complete two science courses in plant \& animal physiology and soil physics. A minimum of three technical electives must be taken from the following topics: crop preservation, design of light-frame building systems, design of water management systems, and management of by-products from animal production. In the final category, students must complete three electives that satisfy either "free elective" or "complementary studies elective" slots in the program. A number of courses from the Faculty of Agricultural \& Food Sciences have been identified to provide the Biosystems Engineering student with basic concepts of production agriculture.

\subsection{Biomedical Specialization}

Biomedical engineering is a broad term that covers areas such as rehabilitation engineering, clinical engineering, tissue engineering, medical imaging, and orthopaedics. Engineers with diverse training can make significant contributions in these areas. Mechanical engineers have much to contribute to areas such as orthopaedics while electrical engineers are often instrumental in medical imaging. A fundamental tenet held by professors in the Department of Biosystems Engineering is that Biosystems Engineers who will work in an area related to biomedical engineering should have fundamental knowledge of human anatomy and physiology. Without such fundamental knowledge, it is difficult to envision how devices or systems can be designed to be compatible with the human body. Rather than expecting the engineer to learn the necessary biological content while on the job, the biomedical specialization has been structured to allow such information to be delivered within the program.

In addition to required science courses in human anatomy and physiology, the biomedical specialization requires students to take the following technical electives: bioengineering applications in medicine, design of assistive technology devices, and imaging and spectroscopy for biosystems. An additional three electives must be taken from a list that includes higherlevel physiology courses, biomechanics courses offered from the kinesiology program, and complementary studies courses such as ethics in biomedicine and history of medicine.

\subsection{Bioprocessing Specialization}

Bioprocessing is often defined as the manufacturing of products from biological materials. The products being manufactured include food, animal feed, pharmaceuticals, paper, and chemicals (such as biofuels or bioplastics). Historically, agricultural engineers have been employed in the food and feed industries because of the close connection to the production of these agricultural products. Prior to the development of the bioprocessing specialization at the University of Manitoba, graduates from the Biosystems Engineering program were being hired by the pharmaceutical industry. The required introductory microbiology course is seen as a major asset for careers in this industry.

Currently, there is much interest in the development of renewable fuels generated from cellulosic feedstocks (many of which can be agricultural waste-products). In fact, this represents the largest research group in the Department of Biosystems Engineering at the present time. The interest in renewable fuels generated from 
biological materials will continue for the foreseeable future.

The bioprocessing specialization was developed with the intent of providing engineers for these types of careers. Technical electives in this specialization include: crop preservation, unit operations, bioprocessing for biorefining, management of by-products from animal production, and pollution prevention practices. Additional courses related to food processing and nutrition provide relevant complementary knowledge to engineering students.

\subsection{Environmental Specialization}

There are numerous environmental issues faced by society. The environmental specialization provides engineers with the knowledge to predict environmental impacts due to human developments and to solve problems associated with the environment (i.e., soil contamination, pollution of rivers and lakes, air pollution, wastewater treatment). When one remembers that the environment is filled with living plants and animals (not to mention people!), it is quite obvious to see that knowledge of basic biology is an asset to the environmental engineer.

For many years, the Department of Biosystems Engineering has offered an Environmental Option (which has now been replaced with an Environmental Specialization). There are numerous graduates working for government agencies, engineering consulting firms, and private companies whose work involves some aspect of environmental management (i.e., oil \& gas companies, pharmaceutical company). These graduates are wellrespected for the knowledge and skillset that they bring.

Technical electives in this specialization include: air pollution assessment and management, environmental impact assessment, management of by-products from animal production, design of water management systems, remediation engineering, and pollution prevention practices. Other electives that can be taken by students include environmental ethics, ecology, environmental engineering analysis, environmental economics, and geography courses (i.e., introduction to geographic information systems, geography of natural resources).

\subsection{Sustainable Building Systems Specialization}

There is a growing desire to reduce the ecological footprint associated with residential and commercial buildings. Engineers will gain knowledge in sustainable building practices and the use of renewable energy sources in building systems. Of all five specializations, the sustainable building systems specialization perhaps relies least on a knowledge of biology. The relevance to
Biosystems Engineering is that many of the "sustainable" building practices involve materials of biological origin rather than the more common construction materials of steel and concrete. Such biological materials usually have distinct properties and distinct responses to building loads. Closely associated with sustainable building practices is the desire to create a more natural home environment. Knowledge of human physiology is a definite asset when attempting to create an environment ideally suited to human occupants.

Technical electives in this specialization include: design of light-frame building systems, structural design in wood, and alternative building design. Other courses offered on campus which are available to students in the sustainable building systems specialization include green building \& planning, advanced structures courses from Civil Engineering, and relevant courses from the Faculty of Architecture.

\section{BIOLOGY IN THE CURRICULUM}

Figure 1 depicts a "tomato washer" that was designed and fabricated in 2002 by a team of Biosystems Engineering students for the WERC International Environmental Design Contest at New Mexico State University. This device is extremely useful for illustrating the importance of biology to an engineering design.

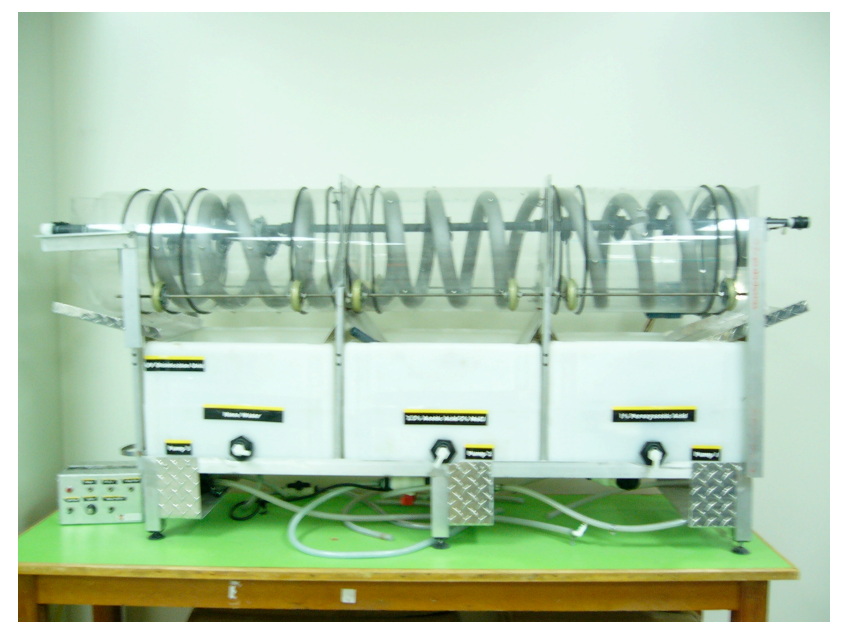

Figure 1: Tomato washer designed and constructed by Biosystems Engineering students for the 2002 WERC International Environmental Design Contest.

Essentially, the challenge was to clean the surface of ripe tomatoes before sending them for sale. Tomatoes irrigated by water containing fecal bacteria can result in these bacteria remaining on the outside surface of the tomatoes at the time of harvest. The device designed by the students was to clean the surface of the ripe tomatoes using minimal resources. The students chose to design a 
continuous-flow rotating-drum washer that would sequentially spray the tomatoes with two solutions of acid and then rinse water while tumbling the ripe tomatoes through the washer. Students were required to have some knowledge of microbiology to establish a strategy that would effectively kill the undesirable bacteria on the surface of the tomatoes. Secondly, students needed to design a washer that was sufficiently gentle so that the ripe tomatoes would not be damaged because they were to be sold as fresh produce. Consequently, they needed to have knowledge of the engineering properties of biological materials. Thus, the success of the continuous-flow rotating-drum washer was enabled by the appropriate application of biological knowledge. This tomato washer is often used in student recruitment activities because it is a visible representation of an engineered device that relied on biological knowledge. There are numerous current engineering problems that can benefit from a similar consideration of biological knowledge.

All engineering programs are required to have a minimum of 195 accreditation units in basic science. The Biosystems Engineering program contains 323 accreditation units of basic science, with approximately one-half classified as "life sciences" (Table 1). In addition to the traditional "basic science" courses of chemistry and physics, the Biosystems Engineering curriculum includes required science courses in biology, physiology, and microbiology. A special "biology for engineers" course teaches the fundamentals of cell biology for viruses, bacteria, plants, and animals. This course has been taught by an engineer, but is currently being taught by a professor with a background in microbiology. All students are required to take an introductory microbiology course that introduces students to the essential characteristics of microbes. Depending on the interest of students, they will then take either a course in human physiology (students pursuing the biomedical specialization) or a course in plant and animal physiology (students pursuing all other specializations). Such courses are intended to introduce the basic concepts of physiology including the mechanisms regulating homeostasis and physiological responses to the environment. Students pursuing one of the specializations may take additional biology courses (i.e., anatomy is taken by students in the biomedical specialization, advanced-level physiology courses may be chosen by students in the biomedical specialization, ecology may be chosen by students in the environmental specialization). Thus, all Biosystems Engineering students will complete a minimum of 3 biology-related courses (out of the 45 courses in the program). In the biomedical specialization, students may complete up to 4 additional biology-related courses. A relatively small proportion of the curriculum is able to provide the necessary basis for an engineering student.
Stand-alone biology courses are not the only means by which Biosystems Engineering students gain an understanding of how to incorporate biological considerations into engineering analysis or design. Core courses such as "engineering properties of biological materials" and "mechanics of materials in biosystems" provide opportunities for engineering students to learn the relationship between composition, structure, and properties of biological materials; the mechanical properties of biological materials; the thermal properties of biological materials; and how biological materials behave when subjected to external loads. Other courses, such as "unit operations" provide instruction related to equipment and systems used in handling, mixing, size reduction, separation and size enlargement of value-added food products.

Table 1. Summary of basic science content in the Biosystems Engineering curriculum. Courses marked with * are biology courses.

\begin{tabular}{|l|l|}
\hline Course title & \multicolumn{1}{|c|}{$\begin{array}{c}\text { Specify } \\
\text { relevant } \\
\text { content }\end{array}$} \\
\hline $\begin{array}{l}\text { CHEM } 1300 \text { Structure and Modelling in } \\
\text { Chemistry }\end{array}$ & Chemistry \\
\hline CHEM 1310 University Chemistry 1 & Chemistry \\
\hline ENG 1460 Thermal Sciences & Physics \\
\hline PHYS 1050 Physics 1: Mechanics & Physics \\
\hline BIOE 2590 Biology for Engineers* & Life Science \\
\hline $\begin{array}{l}\text { MBIO } 1220 \text { Essentials of Microbiology* } \\
\text { or } \\
\text { MBIO } 1010 \text { Microbiology I* }\end{array}$ & Life Science \\
\hline $\begin{array}{l}\text { BIOL } 1410 \text { Anatomy of the Human Body* } \\
\text { or } \\
\text { SOIL } 4060 \text { Body or Physical Properties of } \\
\text { Soil }\end{array}$ & Life Science \\
\hline $\begin{array}{l}\text { BIOL } 1412 \text { Physiology of the Human Body* } \\
\text { or } \\
\text { AGRI } 2200 \text { Principles of Plant and Animal } \\
\text { Physiology* }\end{array}$ & Life Science \\
\hline
\end{tabular}

A final element of the curriculum that may provide an opportunity to apply biological considerations to an engineering problem is the "graduation project" course. All Biosystems Engineering students are required to complete a graduation project which is typically an experimental research project in an area of research represented by faculty members in the Department. Most of the research conducted in the Department has some relevance to a biological entity or biological system. 


\section{CONCLUDING THOUGHTS}

There are appropriate roles to be played by all types of engineers. This article is not attempting to elevate the discipline of Biosystems Engineering above any other engineering discipline. Rather, the purpose is to articulate the rationale behind the development of an engineering discipline that includes biology as one of its foundational elements. Both the history of the discipline (agricultural engineering) and the current trends (represented by new specializations that have been developed) reflect engineering problems where knowledge of biology is a definite asset. It is anticipated that the discipline of Biosystems Engineering will continue to have a role to play well into the foreseeable future. It remains our task to provide the best possible engineering education for this unique discipline.

\section{Acknowledgements}

The author would like to acknowledge the entire academic staff of the Department of Biosystems Engineering. Although most academic staff have expertise in a single area, and therefore, are most "interested" in only one of the areas of specialization, there was unanimous support for introduction of all five of these specializations within the Biosystems Engineering program. The collective vision of the academic staff is appreciated. 